\title{
Prolonged Operative Duration Increases Risk of Surgical Site Infections: A Systematic Review
}

\author{
Hang Cheng,, Brian Po-Han Chen, Ireena M. Soleas, Nicole C. Ferko,2 \\ Chris G. Cameron, and Piet Hinoul ${ }^{1}$
}

\begin{abstract}
Background: The incidence of surgical site infection (SSI) across surgical procedures, specialties, and conditions is reported to vary from $0.1 \%$ to $50 \%$. Operative duration is often cited as an independent and potentially modifiable risk factor for SSI. The objective of this systematic review was to provide an in-depth understanding of the relation between operating time and SSI.

Patients and Methods: This review included 81 prospective and retrospective studies. Along with study design, likelihood of SSI, mean operative times, time thresholds, effect measures, confidence intervals, and p values were extracted. Three meta-analyses were conducted, whereby odds ratios were pooled by hourly operative time thresholds, increments of increasing operative time, and surgical specialty.

Results: Pooled analyses demonstrated that the association between extended operative time and SSI typically remained statistically significant, with close to twice the likelihood of SSI observed across various time thresholds. The likelihood of SSI increased with increasing time increments; for example, a 13\%, 17\%, and 37\% increased likelihood for every $15 \mathrm{~min}, 30 \mathrm{~min}$, and $60 \mathrm{~min}$ of surgery, respectively. On average, across various procedures, the mean operative time was approximately $30 \mathrm{~min}$ longer in patients with SSIs compared with those patients without. Conclusions: Prolonged operative time can increase the risk of SSI. Given the importance of SSIs on patient outcomes and health care economics, hospitals should focus efforts to reduce operative time.
\end{abstract}

Keywords: operative time; surgery, surgical site infection; systematic review

$\mathbf{S}^{\mathrm{s}}$ URGICAL SITE INFECTIONS (SSIs) account for approximately $20 \%$ of nosocomial infections and are a major cause of morbidity, mortality, and health care costs [1-3]. The incidence of SSIs can vary across surgical procedures, specialties, and conditions, with a range of $0.1 \%$ to $50.4 \%$ reported in a systematic review by Korol et al. [4]. Although there are global variations around the definition of an SSI, an SSI is defined typically as infections occurring within 30 days after surgery and affecting either the incision, organs, or body spaces at the site of the operation [5]. In many regions, SSIs are part of reportable hospital acquired conditions that have potential for decreased reimbursement [6].

There are several procedure- and patient-related factors that can contribute to the incidence of SSI. Most studies assessing the likelihood of SSI are observational in design, because multiple risk factors must be evaluated to identify important correlations and associations. In one systematic review of 57 studies, Korol et al. [4] reported that risk factors identified consistently as associated with SSI incidence included comorbidities, advanced age, patient frailty, and surgical complexity. Specifically, 13 studies considered diabetes mellitus as a risk factor in multivariable analyses. In addition, longer surgeries were associated with increased SSI incidence, with a median odds ratio of 2.3 across 11 studies reporting significant results. In a systematic review of 15 studies, Gibbons et al. [7] also reported several factors to be associated consistently with SSIs including pre-operative length of stay and operative duration. Finally, it is recognized that the classification of the

\footnotetext{
${ }^{1}$ Ethicon Inc., Cincinnati, Ohio.

${ }^{2}$ Cornerstone Research Group, Burlington, Ontario, Canada.

(C) Hang Cheng et al., 2017; Published by Mary Ann Liebert, Inc. This Open Access article is distributed under the terms of the Creative Commons Attribution Noncommercial License (http://creativecommons.org/licenses/by-nc/4.0/) which permits any noncommercial use, distribution, and reproduction in any medium, provided the original author(s) and the source are credited.
} 
surgical procedure as clean, clean-contaminated, or contaminated is an important factor in the development of SSIs [8,9].

Published systematic reviews focus on a range of risk factors associated with SSI, both controllable and uncontrollable, but do not focus in depth on the analysis of any one risk factor. Operative time is often cited as an independent predictor of SSI $[1,4,10-13]$ that represents a modifiable risk factor unlike some factors mentioned previously, such as diabetes mellitus or wound classification.

The objective of this study was to conduct a systematic review of prospective and retrospective studies to examine the relation between operative duration and incidence of SSI across surgical specialties. The ultimate goal of this assessment is to provide a more in-depth understanding of this relation for the purpose of informing aspects of operative time that can be managed to improve outcomes.

\section{Patients and Methods}

\section{Search strategy}

Literature was searched from PubMed, the Cochrane Central Register of Controlled Trials (CENTRAL), and Cochrane Database of Systematic Reviews (CDSR) on April 19, 2015. The search strategy was limited to articles published in the English language between January 2005 and January 2015. The search strategy required combinations of the following broad key terms: surgery, operative time, economics, post-operative, intra-operative, infection, post-operative complications, intra-operative complications. This search was supplemented by a targeted search of identified relevant articles in the bibliographies of full-text articles screened and through a similar articles search in PubMed.

\section{Study selection}

Study inclusion criteria were defined according to PICOS (i.e., population, intervention, comparator, outcomes, and study design). All systematic reviews, meta-analyses, randomized controlled trials (RCTs), and observational studies (prospective or retrospective) reporting an effect measure for the association between operative duration and SSI in humans undergoing any type of surgery, were considered for inclusion. Studies were then excluded if they were duplicates; non-full-text articles; published in the form of case reports, letters, comments, or editorials; not in human subjects; and not a relevant study design. Potential study eligibility based on inclusion criteria was evaluated in a title and abstract review, followed by a full-text screening in articles for which the abstract review suggested potential eligibility. The reasons for exclusion were documented for articles excluded at any stage of screening.

\section{Data extraction}

Two reviewers extracted data from full-text articles. The following parameters were extracted: study author (and year); study time frame; sample size; study design; number and types of surgeries; incidence of SSI; study objective; effect measures reporting the association between SSI and operative duration; mean operative time; $p$ values and confidence intervals; and definitions of operative time and SSI if available. Study authors were not contacted to retrieve missing data because of the large volume of studies. Effect measures typically included odds ratios, however, a small portion of studies reported risk ratios or mean operative duration according to presence or absence of infection. Where available, adjusted effect measures were extracted and reported in this review. If multivariable analyses were not conducted, unadjusted effect measures were extracted when available and noted. Furthermore, increased surgical duration was defined typically as a continuous measure per minute(s) of surgery or relative to a cutoff point. If an association was noted for more than one type of SSI (e.g., deep SSI, superficial SSI) data were mainly reported for overall SSIs, unless otherwise specified. Finally, if study result units were reported in minutes, results were converted to hours for consistency in presentation of results and ease of interpretation.

\section{Pooling of study data}

Three types of analyses were completed to examine the quantitative relation between operative time and likelihood of SSI. First, studies were pooled by hourly operative time thresholds (e.g., $<1 \mathrm{~h}$ versus $>1 \mathrm{~h}$ ). For this analysis, studies that reported adjusted odds ratios, as well as operative time thresholds that fell within $20 \%$ of the hour, were included. Second, studies that did not report a specific operative time threshold, rather increments of increased operative time (e.g., likelihood of SSI per minute, per $30 \mathrm{~min}$, etc.), were pooled if they reported adjusted odds ratios. Last, all studies reporting an operative time threshold and adjusted odds ratio were pooled and analyzed by surgical specialty. All study data were pooled using Review Manager (version 5.3, The Nordic Cochrane Centre, The Cochrane Collaboration, Copenhagen, Denmark). Odds ratios were pooled using the generic inverse-variance method, and a random effects model was used. Heterogeneity of the included studies was assessed using the $\chi^{2}$ test and $I^{2}$ measure.

\section{Results}

A total of 4,343 studies were identified from database searching, and 213 additional studies were identified through PubMed similar searches, and manual bibliography searches (Fig. 1). Of the 4,556 citations identified in the search, 2,349 were further excluded after title and abstract screening. Of these, 2,207 underwent full text review, and 2,126 were excluded for various reasons (Fig. 1). Major reasons for exclusion included: outcomes of interest were not reported, studies did not report on operating room or surgical time/ duration, and data were only reported in procedures that were not considered surgical procedures and/or procedures not performed by surgeons (e.g., angioplasty and stent procedures performed by radiologist, dental procedures, ophthalmologic procedures, and certain urologic procedures, percutaneous). Overall, 81 studies were included in this systematic review [1,4-7,10-85].

In total, our review identified three systematic reviews [4,7] and/or meta-analyses [85] and three RCTs [37,39,46], with the remaining 75 studies having an observational design. Of these observational studies, 54 (72\%) were retrospective cohort studies, $18(24 \%)$ were prospective cohort studies, and three were retrospective case-control studies (4\%; Table 1). Many retrospective cohort studies were based on data available through national surveillance databases or gathered through records at hospital center(s). The sample size of the included studies ranged from 66 to 964,128 patients. As per the American College of Surgeons (ACS) [86] categorization 


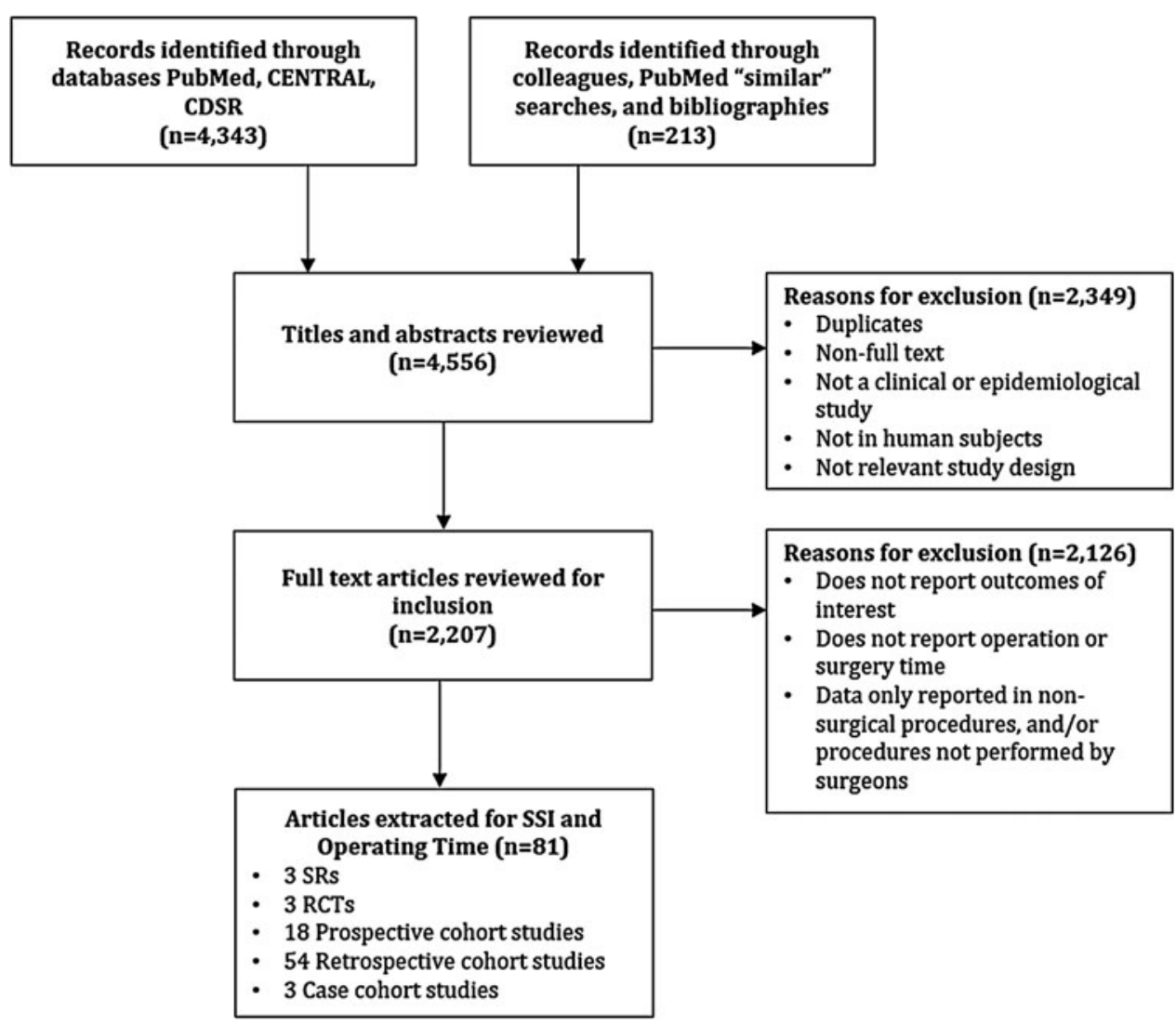

FIG. 1. Preferred Reporting Items for Systematic Reviews and Meta-Analyses (PRISMA) diagram of study selection in the systematic literature search.

Table 1. Summary of Study Design of Included Studies

Study design

Randomized controlled trial

Prospective cohort study

Retrospective cohort study

Retrospective case control study

Systematic review and Meta-analysis
Reference

Theophilus et al. (2011), Chunder et al. (2012), Williams et al. (2013)

Sato et al. (2011), Short et al. (2011), Anaya et al. (2012), Pathak et al. (2014), Opoien et al. (2007), Watanabe et al. (2008), Harbarth et al. (2008), Korinek et al. (2005), Uchino et al. (2013), Howard et al. (2010), Neuman et al. (2014), Valentini et al. (2008), Hubner et al. (2011), Ridgeway et al. (2005), Ogihara et al. (2015), Nagano et al. (2014), Khoshbin et al. (2014), Utsumi et al. (2010)

Nanashima et al. (2014), Kremers et al. (2015), Naranje et al. (2015), Winocour et al. (2015), Nguyen et al. (2012), Showalter et al. (2013), Han et al. (2014), Li et al. (2013), Biscione et al. (2007), Boltz et al. (2011), Davis et al. (2013), Sergeant et al. (2008), Kiran et al. (2010), Drosdeck et al. (2013), Kurmann et al. (2011), Maoz et al. (2015), Mraovic et al. (2011), Zhan et al. (2014), Ata et al. (2010), Suzuki et al. (2010), Haridas et al. (2008), Elola-Olaso et al. (2012), Mahdi et al. (2014), Hagihara et al. (2012), Suehiro et al. (2008), Colman et al. (2013), Nakahira et al. (2013), Bures et al. (2014), Astagneau et al. (2009), Namba et al. (2013), Sadamori et al. (2013), Ogihara et al. (2009), Smith et al. (2012), Alavi et al. (2010), Miki et al. (2006), Lake et al. (2013), Hellinger et al. (2009), Lin et al. (2014), Tran et al. (2015), Elfenbein et al. (2014), Lee et al. (2011), Ma et al. (2012), Campbell et al. (2008), George et al. (2011), Aimaq et al. (2011), Wick et al. (2009), Freire et al. (2013), Fukuda et al. (2013), Herruzo et al. (2013), Cordero-Ampuero et al. (2010), WillisOwen et al. (2010), Stremitzer et al. (2010), Kohut et al. (2015), Skramm et al. (2012)

Kourbatova et al. (2005), Peersman et al. (2006), Lopez-Ben et al. (2014)

Korol et al. (2013), Gibbons et al. (2011) Mavros et al. (2011) 
Table 2. Distribution of Surgical Specialties ACRoss InCluded STUdies ${ }^{\mathrm{a}}$

\begin{tabular}{lcc}
\hline & \multicolumn{2}{c}{ Studies included $(\mathrm{N}=81)$} \\
\cline { 2 - 3 } Surgery type & $\mathrm{n}$ & \multicolumn{1}{c}{$\%$} \\
\hline General surgery & 16 & 19.8 \\
Colon and rectal surgery & 11 & 13.6 \\
Obstetrics and gynecology & 5 & 6.3 \\
Gynecologic oncology & 3 & 3.8 \\
Neurologic surgery & 4 & 5.0 \\
Orthopedic & 16 & 20.0 \\
Otolaryngology & 4 & 5.0 \\
Mixed surgical specialties $^{\mathrm{b}}$ & 22 & 27.2 \\
\hline
\end{tabular}

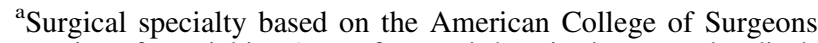
categories of specialties (www.facs.org/education/resources/medicalstudents/faq/specialties).

${ }^{\mathrm{b}}$ Includes three systematic reviews.

of surgical specialties, most studies assessed surgical procedures in mixed surgical specialties $(27.2 \%)$, orthopedic surgery $(20.0 \%)$, and general surgery $(19.8 \%)$ (Table 2). More than half of the studies (56.4\%) used the U.S. Centers for Disease Control and Prevention (CDC) surveillance criteria for the definition of SSI definition, $12.8 \%$ used the American College of Surgeons National Surgical Quality Improvement Program ${ }^{\circledR}$ (ACS NSQIP ${ }^{\circledR}$; American College of Surgeons, Chicago, IL) definition, 8.9\% used definitions other than CDC or ACS-NSQIP, and 21.8\% did not report any information on definition of SSI. This pattern was consistent across all surgical disciplines. Only four (4.9\%) of the included studies clearly defined operative time as either the time from incision-to-close [16,48,52], or time from incision to dressing placement [49]. The majority of studies (58\%) reported a follow-up time of $30 \mathrm{~d}$ after the surgery (Table 3 ). Studies mainly originated from the United States (46\%) or Japan (17\%) followed in frequency by studies from China (3.7\%), Switzerland (3.7\%), United Kingdom (3.7\%), Brazil $(2.4 \%)$, Australia (1.2\%), and Germany (1.2\%). Table 3 provides details on all study methods and results by surgery type.

This systematic review demonstrated that prolonged surgery duration was associated with a statistically significant increased incidence of SSI in the majority of studies. Specifically, $100 \%$ (3/3) of RCTs, $89 \%$ (16/18) of prospective cohort studies, and $86 \%$ (49/57) of retrospective cohort and case control studies reported one or more statistically significant results. A statistically significant association for longer operative time was observed across all included multicenter studies, with the exception of one study [49], whereas approximately $95 \%$ of studies with a sample size of 1,000 or more patients reported a statistically significant association. Many studies reported that operative time was one of only a few independent predictors of SSI $[1,10-13,29,30,33,38$ $42,45,48,52,56,57]$. A few studies even noted that extended operative time was the most important (or only) risk factor for SSI $[18,46,51]$. The incidence of SSI was reported to be $10 \%$ or higher in approximately half $(46 \%)$ of the included studies (Table 3).

Pooled analyses demonstrated that the likelihood of SSI increased by close to twofold in surgeries exceeding operative cutoff times of one, two, three, or four hours, and close to threefold in surgeries exceeding five hours (Table 4). For example, across surgical categories, results demonstrated that there was an $80 \%$ increase in likelihood of SSI with surgeries longer (versus shorter) than three hours (Table 4). Interestingly, pooled analyses further demonstrated that the odds of developing an SSI increased with increasing operative time increments (Table 4). This relation typically remained statistically significant across categories of time. For example, the likelihood of SSI was observed to increase by $5 \%$ for every $10 \mathrm{~min}$ of surgery, $13 \%$ for every $15 \mathrm{~min}$ of surgery, $17 \%$ for every $30 \mathrm{~min}$ of surgery, and $37 \%$ for every $60 \mathrm{~min}$ of surgery. Of studies reporting mean operative time for patients with and without SSI, patients who developed an SSI had a mean duration that was, on average, $0.82 \mathrm{~h} \pm 1.13$ (median $=0.5 \mathrm{~h}$ ) longer than those without SSI (Table 5). When removing two studies $[80,82]$ that appear to be outliers, the recalculated mean operating time difference is $0.55 \pm 0.18 \mathrm{~h}$, more consistent with the $0.5 \mathrm{~h}$ median duration originally calculated across studies. Overall, across a wide range of procedures, patients who developed an SSI had an average operative time that was approximately 30 min longer in duration than those without an SSI (Table 5).

\section{General surgery}

The incidence of SSI varied from $1.4 \%$ to $35 \%$ in the 20 observational studies reported for general surgery (e.g., cholecystectomy, appendectomy, hepatic re-section, mastectomy). Studies with a defined operative time threshold (i.e., ranging from $\geq 2$ versus $<2 \mathrm{~h}$ to $\geq 8$ versus $<8 \mathrm{~h}$ ), reported odds ratios that varied from 0.86 to 4.17 , and the estimated (or reported) relative risk, where available, ranged from 1.19 to 2.83. The four studies that reported unadjusted results tended to have a lower effect size. The mean overall operative time across studies was $3.5 \mathrm{~h}$. In general, at operative times $14 \%$ or more than the mean (e.g., $>4 \mathrm{~h}$ ), the adjusted odds ratio for SSI ranged from 1.41 to 2.90. Pooled analyses within the general surgery sub-group, irrespective of time threshold, demonstrated a statistically significant association between operative time and SSI ( $\mathrm{p}<0.0001$; Table 6).

\section{Colon and rectal surgery}

The incidence of SSI varied from $3.5 \%$ to $25 \%$ in 11 observational studies. For the six studies with a defined time cutoff point (i.e., $>1.8$ versus $<1.8$ hours to $>4$ versus $\leq 4$ hours), the adjusted odds ratio varied from 1.41 to 2.61 . The mean overall operative time across studies was calculated to be 2.7 hours. Typically, at operative cutoff times $11 \%$ or more than the mean (i.e., $>3 \mathrm{~h}$ ), the adjusted odds ratio for SSI ranged from 1.41 to 2.61 . Pooled analyses for the colon and rectal surgery sub-group, irrespective of time threshold, demonstrated a statistically significant association, with a $30 \%$ increased likelihood of SSI with increased operative duration $(\mathrm{p}<0.0001$; Table 6$)$.

\section{Obstetrics and gynecology}

The incidence of SSI ranged from $7 \%$ to $13.8 \%$ in two reported RCTs (cesarean deliveries). Four observational studies evaluated obstetric and gynecologic procedures such as hysterectomy and cesarean delivery. The incidence of SSI varied from $1.1 \%$ to $10.8 \%$. The overall mean operative time 


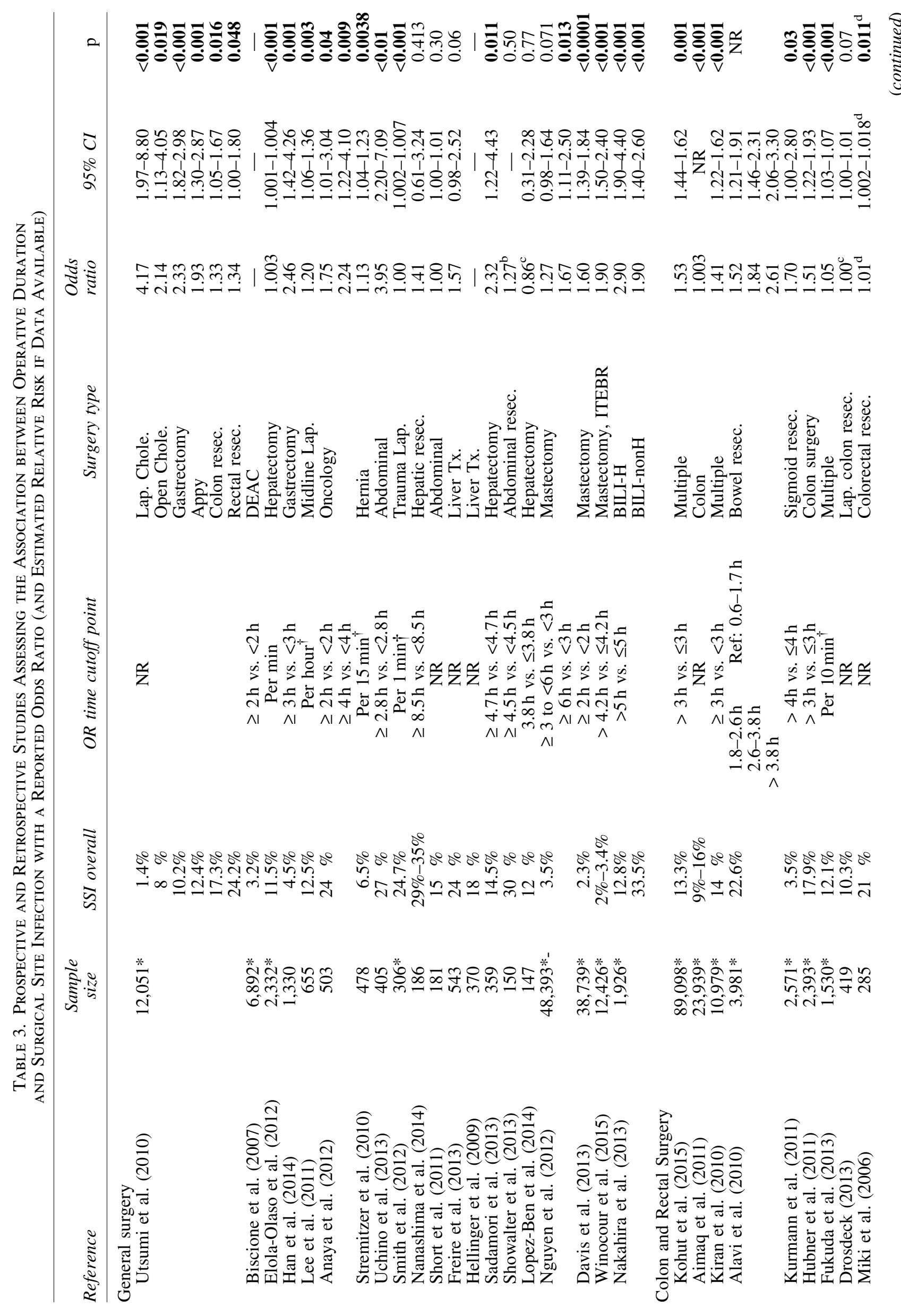




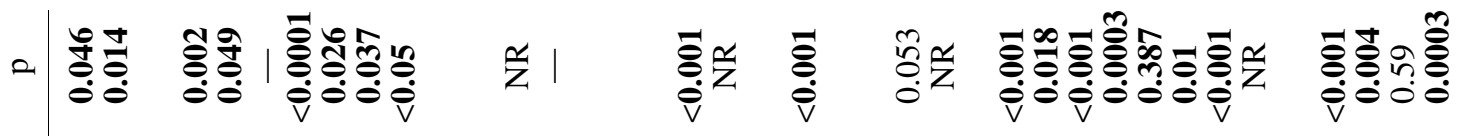

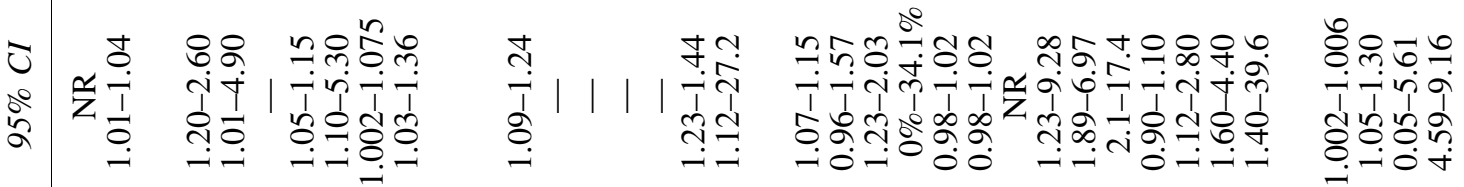

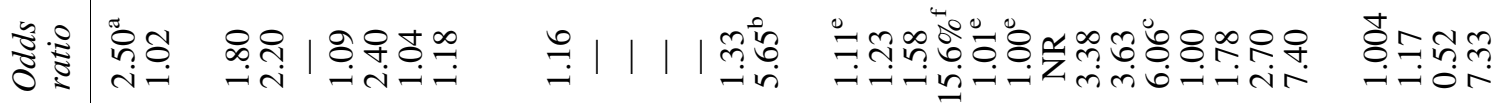
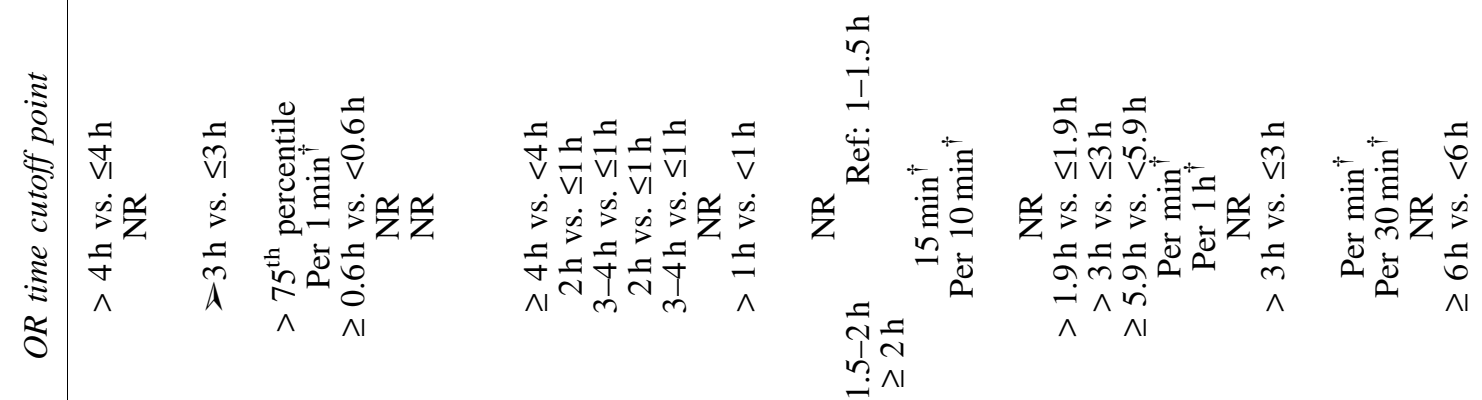

)

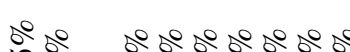

se ge

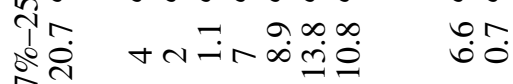

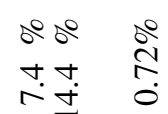

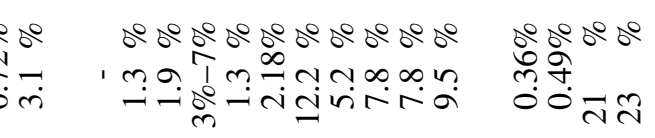

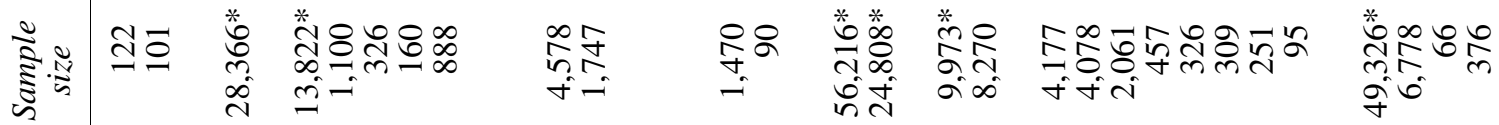
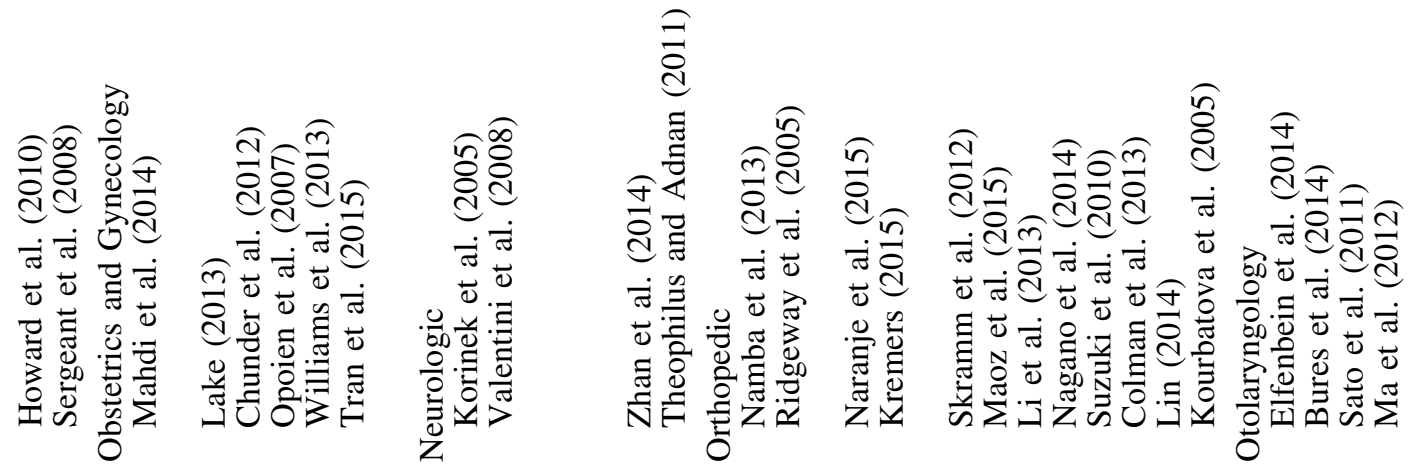


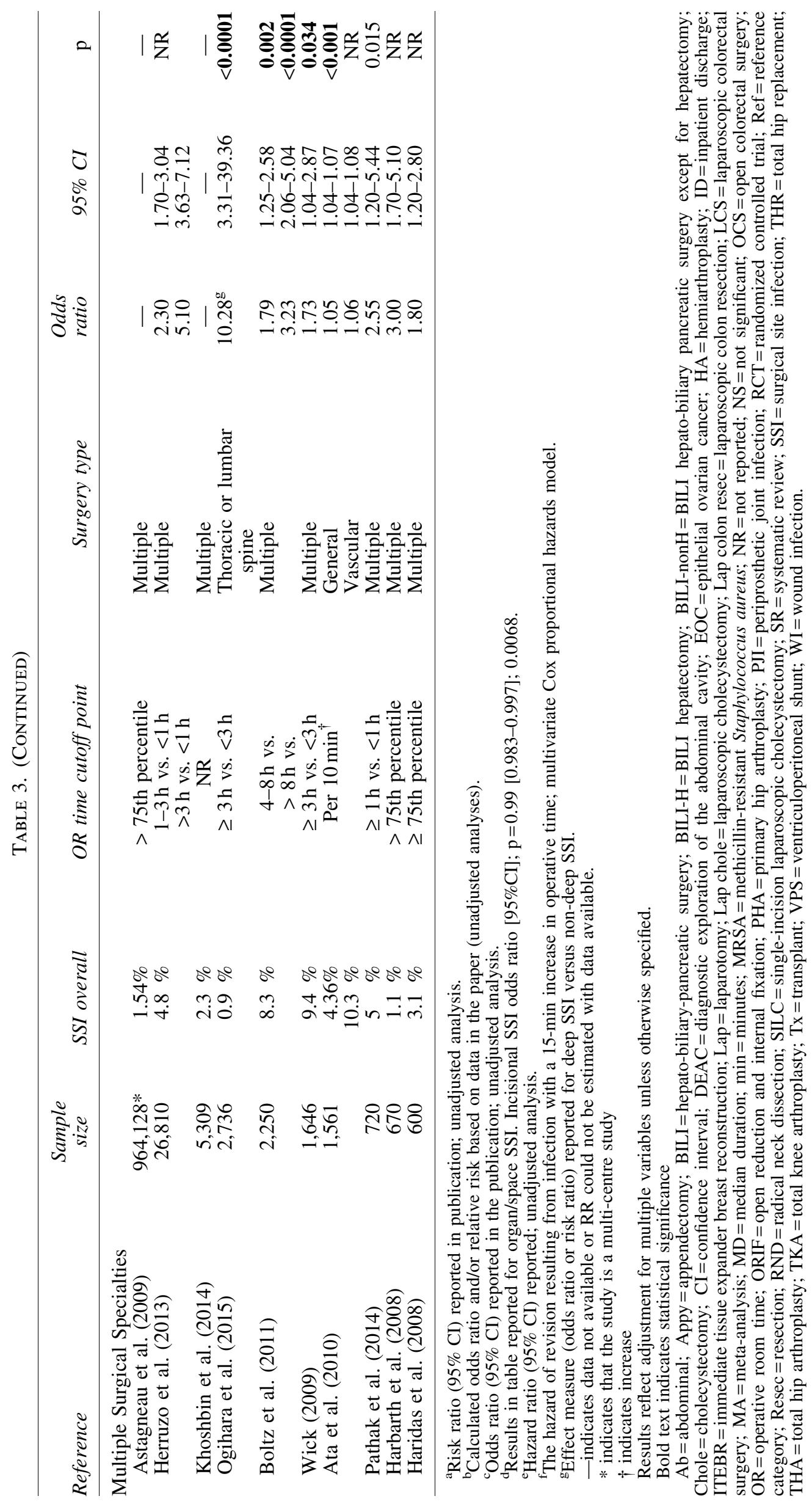


Table 4. Pooled Adjusted Odds Ratios for Surgical Site Infection By Operative Time Threshold or InCREASING InCREMENTS OF TIME

\begin{tabular}{|c|c|c|c|c|c|}
\hline Pooling subgroup & $\begin{array}{c}\text { Number of } \\
\text { studies included }\end{array}$ & Odd & ratio $(95 \%$ CI) & $\mathrm{p}$ & $I^{2}$ \\
\hline \multicolumn{6}{|c|}{ Pooled ORs for SSI by operative time thresholds } \\
\hline$\geq 1 \mathrm{~h}$ vs. $<1 \mathrm{~h}$ & 2 & 2.33 & $(1.78$ & $<0.00001$ & $0 \%$ \\
\hline$\geq 2 \mathrm{~h}$ vs. $<2 \mathrm{~h}$ & 3 & 1.65 & $(1.38$ & $<0.00001$ & $6 \%$ \\
\hline$\geq 3 \mathrm{~h}$ vs. $<3 \mathrm{~h}$ & 11 & 1.80 & $(1.52$ & $<0.00001$ & $73 \%$ \\
\hline$\geq 4$ h vs. $<4 \mathrm{~h}$ & 4 & 1.62 & $(1.13$ & 0.010 & $86 \%$ \\
\hline$\geq 5 \mathrm{~h}$ vs. $<5 \mathrm{~h}$ & 2 & 2.71 & $(1.91$ & $<0.00001$ & $0 \%$ \\
\hline$\geq 6 \mathrm{~h}$ vs. $<6 \mathrm{~h}$ & 1 & 7.33 & $(5.19,10.35)$ & $<0.00001$ & Too few studies to inform $(<2)$ \\
\hline \multicolumn{6}{|c|}{ Pooled ORs for SSI by increasing increments of operative time } \\
\hline Per $1 \mathrm{~min}$ & 5 & 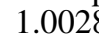 & $(0.9995,1.0062)$ & 0.09 & $79 \%$ \\
\hline Per $10 \min$ & 2 & 1.05 & $(1.04, \quad 1.06)$ & $<0.00001$ & $0 \%$ \\
\hline Per 15 min & 1 & 1.13 & $(1.04$ & 0.004 & Too few studies to inform $(<2)$ \\
\hline Per 30 min & 1 & 1.17 & $(1.05$ & 0.004 & Too few studies to inform $(<2)$ \\
\hline Per 60 min & 2 & 1.37 & $(0.95$ & 0.09 & $62 \%$ \\
\hline
\end{tabular}

$\mathrm{OR}=$ odds ratio $\mathrm{CI}=$ confidence interval; $\mathrm{SSI}=$ surgical site infection.

in this specialty was calculated to be $2.6 \mathrm{~h}$. At an operative cutoff time $15 \%$ or greater than the mean (i.e., $>3 \mathrm{~h}$ ), the incidence of SSIs increased by close to twofold in one study [35]. Interestingly, at an operative time greater than $0.6 \mathrm{~h}$, which is a threshold that is well below the mean operative time, SSI incidence also increased by approximately twofold [38]. This finding appears to hold true whether procedures are open or laparoscopic [35]. Pooled analyses for obstetrics and gynecology surgery, irrespective of time threshold, demonstrated a statistically significant association, with a $14 \%$ increased likelihood of SSI with increased operative duration $(\mathrm{p}=0.005$; Table 6$)$.

\section{Neurologic surgery}

There were three observational studies, and one RCT that evaluated neurosurgical procedures (i.e., craniotomies, ventriculoperitoneal shunt [VPS] insertion). The incidence of SSI varied from $0.7 \%$ to $14.4 \%$. Unadjusted results suggest that the larger the gap in operating time between two study groups, the larger the incidence of SSI. For example, one study reported statistically significant (unadjusted) relative risk results ranging from 12.6 ( $>2 \mathrm{~h}$ versus $<1 \mathrm{~h}$ ) to 24.3 (3$4 \mathrm{~h}$ versus $<1 \mathrm{~h}$ ) in craniotomy and spinal operations. The relative risk doubled as the gap in time between the low and

Table 5. Prospective and Retrospective Studies Assessing the Association between Mean Operative Duration and Surgical Site Infection

\begin{tabular}{|c|c|c|c|c|c|c|c|c|}
\hline \multirow[b]{2}{*}{ Reference } & \multirow{2}{*}{$\begin{array}{l}\text { Sample } \\
\text { size }\end{array}$} & \multirow[b]{2}{*}{$\operatorname{SSI}(\%)$} & \multirow{2}{*}{$\begin{array}{l}\text { Follow-up } \\
\text { time for SSI } \\
\text { surveillance }\end{array}$} & \multirow[b]{2}{*}{ Surgery type } & \multicolumn{2}{|c|}{$\begin{array}{c}\text { Mean operative } \\
\text { time }\end{array}$} & \multirow{2}{*}{$\begin{array}{c}\text { Time } \\
\text { difference }\end{array}$} & \multirow[b]{2}{*}{$\mathrm{p}$} \\
\hline & & & & & SSI & No SSI & & \\
\hline Hagihara et al. (2012) & 304 & $15.1 \%$ & $48 \mathrm{~h}$ & $\begin{array}{l}\text { Colorectal } \\
\text { resection }\end{array}$ & $3.3 \mathrm{~h}$ & $2.7 \mathrm{~h}$ & $0.6 \mathrm{~h}$ & $<0.05$ \\
\hline Suehiro et al. (2008) & 228 & $12.2 \%$ & NR & Digestive & $3.3 \mathrm{~h}$ & $2.4 \mathrm{~h}$ & $0.9 \mathrm{~h}$ & 0.01 \\
\hline Willis-Owen et al. (2010) & 5,277 & $0.98 \%$ & $30 \mathrm{~d}$ & THA, TKR, UKR & $2.1 \mathrm{~h}$ & $1.7 \mathrm{~h}$ & $0.4 \mathrm{~h}$ & $<0.001$ \\
\hline Mraovic et al. (2011) & 1,948 & - & $2 y$ & $\begin{array}{l}\text { Primary THA } \\
\text { or TKA }\end{array}$ & $2.3 \mathrm{~h}$ & $1.8 \mathrm{~h}$ & $0.5 \mathrm{~h}$ & $<0.001$ \\
\hline Peersman et al. (2006) & 353 & - & NR & TKA & $2.1 \mathrm{~h}$ & $1.5 \mathrm{~h}$ & $0.6 \mathrm{~h}$ & $<0.001$ \\
\hline $\begin{array}{l}\text { Cordero-Ampuero } \\
\text { and de Dios (2010) }\end{array}$ & 247 & - & NR & $\begin{array}{l}\text { HA } \\
\text { THA }\end{array}$ & $\begin{array}{l}1.5 \mathrm{~h} \\
2.2 \mathrm{~h}\end{array}$ & $\begin{array}{l}1.2 \mathrm{~h} \\
1.6 \mathrm{~h}\end{array}$ & $\begin{array}{l}0.3 \mathrm{~h} \\
0.4 \mathrm{~h}\end{array}$ & $\begin{array}{l}0.000 \\
0.000\end{array}$ \\
\hline Ogihara et al. (2009) & $209^{*}$ & $10 \%$ & $30 \mathrm{~d}$ & Multiple & $8.5 \mathrm{~h}$ & $4.0 \mathrm{~h}$ & $4.5 \mathrm{~h}$ & $<0.0001$ \\
\hline Campbell et al. (2008) & $113,891^{\mathrm{a}}$ & - & $30 \mathrm{~d}$ & Multiple & $1.7 \mathrm{~h}^{\mathrm{b}}$ & $2.1 \mathrm{~h}^{\mathrm{b}}$ & $0.4 \mathrm{~h}$ & 0.03 \\
\hline Watanabe et al. (2008) & $941^{\mathrm{a}}$ & $\begin{array}{c}8 \\
15.5 \%\end{array}$ & $30 \mathrm{~d}$ & $\begin{array}{l}\text { Upper abdominal } \\
\text { Lower abdominal }\end{array}$ & $\begin{array}{l}3.98 \mathrm{~h} \\
3.7 \mathrm{~h}\end{array}$ & $\begin{array}{l}4.0 \mathrm{~h} \\
3.0 \mathrm{~h}\end{array}$ & $\begin{array}{l}0.02 \mathrm{~h} \\
0.7 \mathrm{~h}\end{array}$ & $\begin{array}{c}\text { NS } \\
<0.001\end{array}$ \\
\hline George et al. (2011) & 566 & $2.5 \%$ & 21.5 & Multiple & $3.2 \mathrm{~h}$ & $2.4 \mathrm{~h}$ & $0.8 \mathrm{~h}$ & 0.009 \\
\hline $\begin{array}{l}\text { Neuman and } \\
\text { Grzebieniak (2014) }\end{array}$ & 270 & $12.2 \%$ & $7 \mathrm{~d}$ & Multiple & $1.8 \mathrm{~h}$ & $1.3 \mathrm{~h}$ & $0.5 \mathrm{~h}$ & $<0.05$ \\
\hline
\end{tabular}

${ }^{\mathrm{a}}$ Multicenter study.

${ }^{\mathrm{b}}$ Results are reported for the comparison between low versus high SSI outlier hospitals.

Results are reported as unadjusted, mean operative duration, unless otherwise specified.

$\mathrm{SSI}=$ surgical site infection; THA = total hip arthroplasty; HA = hemiarthroplasty; TKR = total knee replacement; UKR = unicompartmental knee replacement. 
Table 6. Pooled Adjusted Odds Ratios for Surgical Site Infection and Increased Operative Time ${ }^{\mathrm{a}}$ by Surgical Specialty

\begin{tabular}{lcccc}
\hline Surgical specialty & $\begin{array}{c}\text { Number of } \\
\text { studies included }\end{array}$ & Odds ratio $(95 \%$ CI) & $\mathrm{p}$ & $I^{2}$ \\
\hline General surgery & 16 & $1.03(1.02,1.05)$ & $<0.0001$ & $92 \%$ \\
Colon \& rectal & 8 & $1.30(1.22,1.39)$ & $<0.0001$ & $97 \%$ \\
Obstetrics \& gynecology & 5 & $1.14(1.04,1.24)$ & 0.005 & $74 \%$ \\
Neurologic & 2 & $1.24(1.08,1.42)$ & 0.002 & $86 \%$ \\
Orthopedic & 7 & $1.84(1.32,2.56)$ & 0.0003 & $86 \%$ \\
Otolaryngology & 4 & $1.83(1.13,2.97)$ & 0.01 & $98 \%$ \\
Multiple surgical specialties & 8 & $1.61(1.44,1.81)$ & $<0.00001$ & $95 \%$ \\
\hline
\end{tabular}

*The pooled analysis within each surgical specialty represents the association between increased operative time and SSI, whereby increased operative time was variably defined by exceeding different operative time cut-off points.

${ }^{a}$ The pooled analysis within each surgical specialty represents the association between increased operative time and SSI, whereby increased operative time was variably defined by exceeding different operative time cutoff points.

$\mathrm{SSI}=$ surgical site infection; $\mathrm{CI}=$ confidence interval.

high operation durations expanded. Pooled analyses for neurologic surgery, irrespective of time threshold, demonstrated a $24 \%$ increased likelihood of SSI with increased operative duration $(\mathrm{p}=0.002$; Table 6$)$.

\section{Orthopedic surgery}

The incidence of SSI varied from $0.7 \%$ to $12.2 \%$ among the 12 observational studies in this surgical specialty. For the five studies with a defined time cutoff point (i.e., $>1.5$ versus $<1.5 \mathrm{~h}$ to $>6 \mathrm{~h}$ versus $<6 \mathrm{~h}$ ), the reported adjusted odds ratio varied from 1.23 to 7.40 . The mean overall operative time across the studies was calculated to be $2.5 \mathrm{~h}$. An increase in the mean operative time by $20 \%$ or greater (i.e., $\geq 3 \mathrm{~h}$ ) was associated with adjusted odds ratios ranging from 3.63 to 7.40. Pooled analyses for orthopedic surgery, irrespective of operative time threshold, demonstrated a statistically significant association, with an $84 \%$ increased likelihood of SSI with increased operative time $(p=0.0003$; Table 6).

\section{Otolaryngology surgery}

The incidence of SSI ranged between from $0.36 \%$ to $23 \%$ among the four observational studies in otolaryngologic surgery (i.e., thyroid or other). The mean overall operative time could not be estimated for the included studies in this specialty because of limited availability of data. For the one study that reported a time cutoff point (i.e., $\geq 6$ versus $<6 \mathrm{~h}$ ), almost a fivefold increase in incidence was predicted for SSI (estimated relative risk [RR]: 4.7; 95\% confidence interval [CI]: 3.48-5.32). Pooled analyses for otolaryngology surgery demonstrated a statistically significant association, with an $83 \%$ increased likelihood of SSI with increased operative time $(\mathrm{p}=0.01$; Table 6$)$.

\section{Multiple surgical specialty}

There were 12 studies that assessed procedures from multiple surgical specialties. The study time cutoff points typically ranged from more than one versus less than one hour to more than eight versus less than eight hours. The highest likelihood of SSI was observed with posterior thoracic or lumbar spine procedures whereby an odds ratio of 10.28 was observed when operative time exceeded three hours for deep SSI versus non-deep SSI [67]. Pooled analy- ses, irrespective of operative time threshold, demonstrated a $61 \%$ increased likelihood of SSI with increased operative time across specialties $(\mathrm{p}<0.00001$; Table 6).

\section{Review of Published Systematic Reviews}

Our review additionally identified three systematic reviews $[4,7,85]$. A 2013 systematic review of 57 observational studies [4] reported on risk factors associated with SSIs across surgeries. The mean SSI incidence was 3.7\%, ranging from $0.1 \%$ to $50.4 \%$. Among other risk factors (e.g., advanced age, frailty, diabetes mellitus, and surgery complexity), the review reported that increased duration of surgery was found consistently to be associated with SSI. When results were restricted to 16 studies that used a binary time cutoff point to compare shorter versus longer surgeries, 15 of 16 estimates suggested an increased incidence of SSI for longer surgeries. Of these, 11 studies showed statistically significant results, with a median odds ratio of 2.3 (range, 1.2 to 3.8). In a small meta-analysis of hernia repair [85], results demonstrated that duration of operation was statistically significantly associated with the development of hernia mesh infection (weighted mean difference [WMD]: 44.92; 95\% CI [25.66-64.18, p<0.001]). The number of studies included was small ( $n=3$ studies). Finally, a health technology assessment (HTA) that focused on different types of risk factors for SSI reported that multivariable analyses demonstrated consistently that prolonged operative duration was associated with increased incidence for SSI (i.e., coronary artery bypass graft [CABG], abdominal surgery, bowel surgery, limb amputation, open reduction of fracture, vascular surgery, small bowel surgery), however, no trend was observed in hip prosthesis surgery [7].

\section{Discussion}

This comprehensive systematic review is the only published review to our knowledge that focuses solely on the incidence of SSI in relation to extended operating time. Studies were mainly observational in nature given the target research question of assessing association of an outcome (i.e., SSI) with risk factors. Our review demonstrated that the majority of studies $(87 \%)$ reported a statistically significant association between longer operative time and SSI. Pooled 
analyses further demonstrated that the association remained typically statistically significant with close to twice the likelihood of SSI often observed with different hourly time thresholds. The likelihood of SSI was also observed to increase with increasing increments of operative time. In summary, across a wide range of procedures, patients who developed an SSI had an average operative time that was 30 min longer than those without an SSI.

More specifically, approximately $95 \%$ of studies with a sample size of 1,000 or more patients reported a statistically significant association, and $62 \%$ of the studies with a defined operative time threshold reported close to twice the likelihood of SSI when the time point was exceeded. The reported time thresholds varied substantially across studies from greater than $0.6 \mathrm{~h}$ to greater than $8 \mathrm{~h}$, however, definitions of prolonged operative time generally ranged from $11 \%$ to $30 \%$ greater than the mean overall operative time calculated across studies. Within surgical specialties, some of the highest likelihood effect measures were reported in orthopedic surgery (i.e., odds ratio [OR] of 7.40 if exceeds $3 \mathrm{~h}$ [58]) oral or maxillofacial surgery (i.e., OR of 7.33 if exceeds $6 \mathrm{~h}$ [62]), and thoracic and lumbar spine surgery (OR of 10.28 if exceeds $3 \mathrm{~h}[67])$.

An important finding from our pooled analysis was that a linear relation for operative time and likelihood of SSI was observed. There were 11 studies that reported on the association based on per time increments (i.e., per minute, per $10 \mathrm{~min}$, per $15 \mathrm{~min}$, per $30 \mathrm{~min}$, per $60 \mathrm{~min}$ ). The analysis demonstrated that the magnitude of the odds ratio increased as the operative time increments increased. In other words, the analysis demonstrated that the likelihood of SSI increased by $5 \%$ for every $10 \mathrm{~min}$ of time, $13 \%$ for every $15 \mathrm{~min}$ of time, $17 \%$ for every $30 \mathrm{~min}$ of time, and $37 \%$ for every $60 \mathrm{~min}$ of time. In our alternative pooled analysis, whereby results were instead pooled by hourly time thresholds (i.e., $>1$ versus $<1 \mathrm{~h},>2$ versus $<2 \mathrm{~h}$, etc.), a linear trend was not as clearly observed. This finding may likely be because there was no common anchor operative threshold time point for every comparison. We hypothesize that a stronger relation between increasing operative time and likelihood of SSI could have been observed if we had compared each operative time threshold (i.e., $>2 \mathrm{~h},>3 \mathrm{~h},>4 \mathrm{~h}$, etc.) to a common threshold of less than one hour, as the gaps in time grow larger with increasing thresholds. This comparison was not possible because of variability in the thresholds reported across the studies, however, could be made possible with the conduct of a sophisticated network meta-analysis that relies on indirect comparison of results.

Our study focuses uniquely on operative time as a risk factor for SSI because operative time has often been emphasized as being one of few independent risk factors for SSI. Other systematic reviews previously published (e.g., Korol et al. [4], Gibbons et al. [7], Mavros et al. [85]) report on the association between several different types of risk factors and SSI. Although operative time is mentioned as a significant predictor in these reviews, there is a poor understanding of how this risk factor varies across surgery types, the magnitude of the association, and the relation between increasing increments of operative time and SSI. Our study presents this information in detail to provide a comprehensive and up to date evaluation of studies available on this topic. Furthermore, the number of studies included in previous systematic reviews tended to be substantially less than the number of studies reported in our review.

Operative time is an independent risk factor for SSI that may be partially modifiable unlike certain patient risk factors such as presence of diabetes mellitus for instance. There are many parameters that can impact operating time, including pre-operative planning, surgeon experience, surgeon fatigue, operating room staff experience, and access to equipment. The exact mechanisms by which SSI incidence is increased because of prolonged operative time is not fully understood, however, several studies postulate logical reasons. With increased operative time, patients' open incisions are exposed to the environment longer, thus increasing the risk of bacterial contamination. Longer operative time predisposes incisions to tissue desiccation that may also increase the probability of contamination [40,74].

Tissue concentrations of antibiotics will decrease as the procedure continues and may be inadequate if not readministered during the surgical procedure [11,34,87-89]. Unfortunately, almost all included studies did not provide enough information on antibiotic redosing during the surgery. Also, included studies sometimes failed to report enough information on extended antibiotic prophylaxis. Despite most clinical practice guidelines recommending the discontinuation of prophylactic antibiotics within $48 \mathrm{~h}$ of surgery completion, in some countries antibiotic prophylaxis is often extended beyond $48 \mathrm{~h}$ [90-92]. In such regions, surgical site infections may involve multi-drug-resistant pathogens, however, without detailed data, this is speculative. Where we could, we informed our meta-analysis with odds ratios that were adjusted for possible confounders, such as antibiotic use, to try and mitigate bias.

Longer operative times may also mean increased surgical team fatigue and room for more technical errors [53,93,94]. Furthermore, longer operative times often represent more complex surgery procedures [40]. One observational study included in this review specifically reported however that high SSI outlier hospitals had significantly longer operative times compared with low SSI outlier hospitals and that the longer duration of operation was not primarily related to differences in case complexity [81]. Factors such as, patient characteristics, surgeon skill, or intra-operative teaching may play a role in determining operative duration, as well as the efficiency of support staff during surgical procedures [81].

Some of the factors that increase operative time can be modifiable whereas others may not be. In any case, use of measures that may help to lower operating time and optimize work flow should be used. In patients with longer targeted or unexpected surgery times, strict adherence to infection prevention measures is essential [10,95]. Studies have reported that antibiotic dosing during the procedure can be cost effective in higher risk patients [96]. Although surgical procedures should not be unnecessarily shortened, many avoidable factors can introduce delay. Surgical team familiarity with the procedure and equipment should be addressed prior to the procedure. Pre-operative planning can help to reduce the time spent on decision making during the surgery and help to predict materials requirements [76]. The design of device implants or instruments can help minimize the number of steps required in the procedure [76,97]. Furthermore, the standard, expected operative time of a particular surgery may serve as an indicator or guideline for surgical quality and 
the associated risk of complications. In a study reporting the expected operating room time across various surgeries, procedures longer than the expected operative duration (i.e., $>95 \%$ CI of expected operative time) had a significantly greater risk of complications, whereas procedures with shorter than expected durations had a lower risk of post-operative occurrences [98]. In summary, planning, procedure efficiency, and surgeon education should be optimized to minimize the impact of operating time on SSI incidence where possible [52]. In effect, modifiable reductions in operating time can also be expected to significantly reduce costs, as demonstrated by a previous meta-analysis [99].

Our study has some limitations. The majority of studies included in the review were retrospective in nature. It is known that such studies depend on the accuracy, completeness, and type of data available from patient records. Many studies were based on surveillance databases and therefore studies were limited to parameters collected from the database. For example, some databases did not capture the type of antibiotic used. Also, definitions of SSI varied across observational studies which may have contributed to some heterogeneity. However, many of these retrospective studies focused on large, and sometimes national, database sources with robust reporting systems (e.g., ACS-NSQIP) designed to provide reliable risk-adjusted surgical outcomes. It is further noted that the majority of studies adjusted for potential confounding parameters to provide a more accurate estimate of the association between SSI incidence and operative time. It was also observed that prospective cohort study results were generally congruent with retrospective study results despite study design differences. Second, we did not formally assess study quality using an observational study quality assessment scale because of the volume of studies included in this review. However, we did report the study sample size, whether the study was single or multicenter, whether the study was prospective or retrospective, and whether results were adjusted versus unadjusted. Overall, there were no clear trends observed between more rigorously conducted studies (e.g., high sample size, multi-center, prospective) and less rigorously conducted studies, although in one study, relative risks that were unadjusted were reported to be quite high [44]. Given the consistent trends in the significance and magnitude of the results across studies, study design may be less of an important factor in interpretation of the current study results. Third, in analyses where we quantitatively pooled the data to determine how the likelihood of SSI increased with increasing time increments, we were limited by the number of studies that could be included (i.e., $\mathrm{n}=11$ ) given variability in how thresholds were defined across studies. Nevertheless, our analysis did suggest a linear relation of increasing SSI likelihood with increasing increments of time. Further sophisticated methodologies using the breadth of data available, such as network meta-analyses, may help to more precisely characterize the change in risk with different time increments. Fourth, most studies included in this review combined different types of SSI into one overall rate to capture the maximum number of infections and obtain sufficient statistical power. It can be argued that superficial infections as a subtype of overall are less clinically relevant and that attention should focus on deep infections [76]. Often, invasiveness of the infection may be difficult if not impossible to assess [51]. Furthermore, studies that reported on subtypes of SSI, in- cluding deep infection, typically also reported an association between operative time and SSI incidence.

\section{Conclusions}

This study demonstrates comprehensively that prolonged operative time can increase the likelihood of developing SSI across a broad array of surgical procedures and surgical specialties. Overall, pooled analyses demonstrated that patients with extended operative times across a wide range of procedures had approximately twice the likelihood of developing SSI, and on overage, the mean operative time was approximately $30 \mathrm{~min}$ longer in patients with SSIs compared with those patients without SSIs. Nevertheless, given the importance of SSIs on patient outcome and health care economics including hospital reimbursement penalties, hospitals should focus efforts to reduce operative time. This may include strategies such as the adoption of new technologies that can help improve operative efficiency, utilization of specialized care teams, ensuring that operating staff are not overworked or fatigued, and better preoperative planning. These strategies should be considered in light of other possible risk factors for SSI.

\section{Acknowledgments}

This study was funded by Ethicon Inc. H. Cheng and P. Hinoul were involved in conception and design, interpretation of the data, revising paper critically for intellectual content and final approval. N. Ferko and I. Soleas were involved in analyses and interpretation of the data, drafting of the paper, and final approval. C. Cameron and B. Chen were involved in analyses and interpretation of the data, revising the paper critically for intellectual content, and final approval.

\section{Author Disclosure Statement}

The following authors disclosed financial relations to this publication: Hang Cheng and Piet Hinoul are employees of Ethicon, Inc.; Brian Po-Han Chen is a research fellow from Thomas Jefferson University sponsored by Ethicon, Inc. Ireena Soleas, Nicole C. Ferko, and Chris G. Cameron are employees of Cornerstone Research Group, under contract with Ethicon, Inc.

\section{References}

1. Moreno Elola-Olaso A, Davenport DL, Hundley JC, et al. Predictors of surgical site infection after liver resection: A multicentre analysis using National Surgical Quality Improvement Program data. HPB (Oxford) 2012;14:136-141.

2. Perencevich EN, Sands KE, Cosgrove SE, et al. Health and economic impact of surgical site infections diagnosed after hospital discharge. Emerg Infect Dis 2003;9:196-203.

3. Dimick JB, Weeks WB, Karia RJ, et al. Who pays for poor surgical quality? Building a business case for quality improvement. J Am Coll Surg 2006;202:933-937.

4. Korol E, Johnston K, Waser N, et al. A systematic review of risk factors associated with surgical site infections among surgical patients. PLoS One 2013;8:e83743.

5. Hagihara M, Suwa M, Ito Y, et al. Preventing surgical-site infections after colorectal surgery. J Infect Chemother 2012; 18:83-89. 
6. Short SS, Nasseri Y, Gangi A, et al. Deep vein thrombosis prophylaxis increases perioperative surgical site infection in a prospective cohort of patients undergoing colorectal surgery. Am Surg 2011;77:1309-1313.

7. Gibbons C, Bruce J, Carpenter J, et al. Identification of risk factors by systematic review and development of riskadjusted models for surgical site infection. Health Technol Assess 2011;15:1-156.

8. Kanters AE, Krpata DM, Blatnik JA, et al. Modified hernia grading scale to stratify surgical site occurrence after open ventral hernia repairs. J Am Coll Surg 2012;215:787-793.

9. Cruse PJ, Foord R. The epidemiology of wound infection. A 10-year prospective study of 62,939 wounds. Surg Clin North Am 1980;60:27-40.

10. Han JH, Jeong O, Ryu SY, et al. Efficacy of single-dose antimicrobial prophylaxis for preventing surgical site infection in radical gastrectomy for gastric carcinoma. J Gastric Cancer 2014;14:156-163.

11. Alavi K, Sturrock PR, Sweeney WB, et al. A simple risk score for predicting surgical site infections in inflammatory bowel disease. Dis Colon Rectum 2010;53:1480-1486.

12. Kurmann A, Vorburger SA, Candinas D, et al. Operation time and body mass index are significant risk factors for surgical site infection in laparoscopic sigmoid resection: A multicenter study. Surg Endosc 2011;25:3531-3534.

13. Hellinger WC, Crook JE, Heckman MG, et al. Surgical site infection after liver transplantation: risk factors and association with graft loss or death. Transplantation 2009;87: 1387-1393.

14. Utsumi M, Shimizu J, Miyamoto A, et al. Age as an independent risk factor for surgical site infections in a large gastrointestinal surgery cohort in Japan. J Hosp Infect 2010; 75:183-1877.

15. Biscione FM, Couto RC, Pedrosa TM, et al. Factors influencing the risk of surgical site infection following diagnostic exploration of the abdominal cavity. J Infect 2007;55: 317-323.

16. Lee JS, Terjimanian MN, Tishberg LM, et al. Surgical site infection and analytic morphometric assessment of body composition in patients undergoing midline laparotomy. J Am Coll Surg 2011;213:236-244.

17. Anaya DA, Cormier JN, Xing Y, et al. Development and validation of a novel stratification tool for identifying cancer patients at increased risk of surgical site infection. Ann Surg 2012;255:134-139.

18. Stremitzer S, Bachleitner-Hofmann T, Gradl B, et al. Mesh graft infection following abdominal hernia repair: risk factor evaluation and strategies of mesh graft preservation. A retrospective analysis of 476 operations. World J Surg 2010;34:1702-1709.

19. Uchino M, Ikeuchi H, Matsuoka H, et al. Risk factors for surgical site infection and association with infliximab administration during surgery for Crohn's disease. Dis Colon Rectum 2013;56:1156-1165.

20. Smith BP, Fox N, Fakhro A, et al. "SCIP" ping antibiotic prophylaxis guidelines in trauma: The consequences of noncompliance. J Trauma Acute Care Surg 2012;73:452456.

21. Nanashima A, Abo T, Arai J, et al. Clinicopathological parameters associated with surgical site infections in patients who underwent pancreatic resection. Hepatogastroenterology 2014;61:1739-1743.

22. Kohut AY, Liu JJ, Stein DE, et al. Patient-specific risk factors are predictive for postoperative adverse events in colorectal surgery: An American College of Surgeons National Surgical Quality Improvement Program-based analysis. Am J Surg 2015;209:219-229.

23. Aimaq R, Akopian G, Kaufman HS. Surgical site infection rates in laparoscopic versus open colorectal surgery. Am Surg 2011;77:1290-1294.

24. Kiran RP, El-Gazzaz GH, Vogel JD, et al. Laparoscopic approach significantly reduces surgical site infections after colorectal surgery: data from national surgical quality improvement program. J Am Coll Surg 2010;211:232-238.

25. Hubner M, Diana M, Zanetti G, et al. Surgical site infections in colon surgery: The patient, the procedure, the hospital, and the surgeon. Arch Surg 2011;146:1240-1245.

26. Fukuda H, Morikane K, Kuroki M, et al. Toward the rational use of standardized infection ratios to benchmark surgical site infections. Am J Infect Control 2013;41:810 814.

27. Freire MP, Soares Oshiro IC, Bonazzi PR, et al. Surgical site infections in liver transplant recipients in the model for end-stage liver disease era: An analysis of the epidemiology, risk factors, and outcomes. Liver Transpl 2013;19: 1011-1019.

28. Drosdeck J, Harzman A, Suzo A, et al. Multivariate analysis of risk factors for surgical site infection after laparoscopic colorectal surgery. Surg Endosc 2013;27:4574-4580.

29. Sadamori H, Yagi T, Shinoura S, et al. Risk factors for organ/space surgical site infection after hepatectomy for hepatocellular carcinoma in 359 recent cases. J Hepatobiliary Pancreat Sci 2013;20:186-196.

30. Miki C, Inoue Y, Mohri Y, et al. Site-specific patterns of surgical site infections and their early indicators after elective colorectal cancer surgery. Dis Colon Rectum 2006; 49(10 Suppl):S45-52.

31. Showalter SL, Kelz RR, Mahmoud NN. Effect of technique on postoperative perineal wound infections in abdominoperineal resection. Am J Surg 2013;206:80-85.

32. Lopez-Ben S, Palacios O, Codina-Barreras A, et al. Pure laparoscopic liver resection reduces surgical site infections and hospital stay. Results of a case-matched control study in 50 patients. Langenbecks Arch Surg 2014;399:307-314.

33. Howard DP, Datta G, Cunnick G, et al. Surgical site infection rate is lower in laparoscopic than open colorectal surgery. Colorectal Dis 2010;12:423-427.

34. Sergeant G, Buffet W, Fieuws S, et al. Incisional surgical site infections after colorectal surgery: Time to appraise its true incidence. Acta Chir Belg 2008;108:513-517.

35. Mahdi H, Goodrich S, Lockhart D, et al. Predictors of surgical site infection in women undergoing hysterectomy for benign gynecologic disease: A multicenter analysis using the national surgical quality improvement program data. J Minim Invasive Gynecol 2014;21:901-909.

36. Lake AG, McPencow AM, Dick-Biascoechea MA, et al. Surgical site infection after hysterectomy. Am J Obstet Gynecol. 2013;209(5):490 e1-9.

37. Chunder A, Devjee J, Khedun SM, et al. A randomised controlled trial on suture materials for skin closure at caesarean section: Do wound infection rates differ? S Afr Med J 2012;102(6 Pt 2):374-376.

38. Opoien HK, Valbo A, Grinde-Andersen A, et al. Postcesarean surgical site infections according to CDC standards: Rates and risk factors. A prospective cohort study. Acta Obstet Gynecol Scand 2007;86:1097-1102.

39. Williams NL, Glover MM, Crisp C, et al. Randomized controlled trial of the effect of $30 \%$ versus $80 \%$ fraction of 
inspired oxygen on cesarean delivery surgical site infection. Am J Perinatol. 2013;30:781-786.

40. Nguyen TJ, Costa MA, Vidar EN, et al. Effect of immediate reconstruction on postmastectomy surgical site infection. Ann Surg 2012;256:326-333.

41. Davis GB, Peric M, Chan LS, et al. Identifying risk factors for surgical site infections in mastectomy patients using the National Surgical Quality Improvement Program database. Am J Surg 2013;205:194-199.

42. Tran CW, McGree ME, Weaver AL, et al. Surgical site infection after primary surgery for epithelial ovarian cancer: Predictors and impact on survival. Gynecol Oncol. 2015; 136:278-284.

43. Korinek AM, Golmard JL, Elcheick A, et al. Risk factors for neurosurgical site infections after craniotomy: A critical reappraisal of antibiotic prophylaxis on 4,578 patients. $\mathrm{Br} \mathrm{J}$ Neurosurg 2005;19:155-162.

44. Valentini LG, Casali C, Chatenoud L, et al. Surgical site infections after elective neurosurgery: A survey of 1747 patients. Neurosurgery 2008;62:88-95.

45. Zhan R, Zhu Y, Shen Y, et al. Post-operative central nervous system infections after cranial surgery in China: Incidence, causative agents, and risk factors in 1,470 patients. Eur J Clin Microbiol Infect Dis 2014;33:861-866.

46. Theophilus SC, Adnan JS. A randomised control trial on the use of topical methicillin in reducing post-operative ventriculoperitoneal shunt infection. Malays J Med Sci 2011; 18:30-37.

47. Namba RS, Inacio MC, Paxton EW. Risk factors associated with deep surgical site infections after primary total knee arthroplasty: An analysis of 56,216 knees. J Bone Joint Surg Am 2013;95:775-782.

48. Ridgeway S, Wilson J, Charlet A, et al. Infection of the surgical site after arthroplasty of the hip. J Bone Joint Surg Br 2005;87:844-850.

49. Naranje S, Lendway L, Mehle S, et al. Does operative time affect infection rate in primary total knee arthroplasty? Clin Orthop Relat Res 2015;473:64-69.

50. Kremers HM, Lewallen LW, Lahr BD, et al. Do claimsbased comorbidities adequately capture case mix for surgical site infections? Clin Orthop Relat Res 2015;473: 1777-1786.

51. Skramm I, Saltyte Benth J, Bukholm G. Decreasing time trend in SSI incidence for orthopaedic procedures: Surveillance matters! J Hosp Infect 2012;82:243-247.

52. Maoz G, Phillips M, Bosco J, et al. The Otto Aufranc Award: Modifiable versus nonmodifiable risk factors for infection after hip arthroplasty. Clin Orthop Relat Res. 2015; 473(2):453-9.

53. Li GQ, Guo FF, Ou Y, et al. Epidemiology and outcomes of surgical site infections following orthopedic surgery. Am J Infect Control 2013;41:1268-1271.

54. Nagano S, Yokouchi M, Setoguchi T, et al. Analysis of surgical site infection after musculoskeletal tumor surgery: Risk assessment using a new scoring system. Sarcoma 2014; 2014:645496.

55. Suzuki T, Morgan SJ, Smith WR, et al. Postoperative surgical site infection following acetabular fracture fixation. Injury 2010;41:396-399.

56. Colman M, Wright A, Gruen G, et al. Prolonged operative time increases infection rate in tibial plateau fractures. Injury 2013;44:249-252.

57. Lin S, Mauffrey C, Hammerberg EM, et al. Surgical site infection after open reduction and internal fixation of tibial plateau fractures. Eur J Orthop Surg Traumatol 2014;24: 797-803.

58. Kourbatova EV, Halvosa JS, King MD, et al. Emergence of community-associated methicillin-resistant Staphylococcus aureus USA 300 clone as a cause of health care-associated infections among patients with prosthetic joint infections. Am J Infect Control 2005;33:385-391.

59. Elfenbein DM, Schneider DF, Chen H, et al. Surgical site infection after thyroidectomy: A rare but significant complication. J Surg Res 2014;190:170-176.

60. Bures C, Klatte T, Gilhofer M, et al. A prospective study on surgical-site infections in thyroid operation. Surgery 2014; 155:675-681.

61. Sato J, Goto J, Harahashi A, et al. Oral health care reduces the risk of postoperative surgical site infection in inpatients with oral squamous cell carcinoma. Support Care Cancer 2011;19:409-416.

62. Ma CY, Ji T, Ow A, et al. Surgical site infection in elderly oral cancer patients: Is the evaluation of comorbid conditions helpful in the identification of high-risk ones? J Oral Maxillofac Surg 2012;70:2445-2452.

63. Astagneau P, L'Heriteau F, Daniel F, et al. Reducing surgical site infection incidence through a network: Results from the French ISO-RAISIN surveillance system. J Hosp Infect 2009;72:127-134.

64. Herruzo R, Diez-Sebastian J, Mora E, et al. Trends in the incidence of superficial versus deep-organ/space surgical site infection in a tertiary hospital. J Surg Res 2013;184: 1085-1091.

65. Winocour S, Martinez-Jorge J, Habermann E, et al. Early surgical site infection following tissue expander breast reconstruction with or without acellular dermal matrix: National benchmarking using National Surgical Quality Improvement Program. Arch Plast Surg 2015;42:194-200.

66. Khoshbin A, So JP, Aleem IS, et al. Antibiotic prophylaxis to prevent surgical site infections in children: A prospective cohort study. Ann Surg 2014; 262:397-402

67. Ogihara S, Yamazaki T, Maruyama T, et al. Prospective multicenter surveillance and risk factor analysis of deep surgical site infection after posterior thoracic and/or lumbar spinal surgery in adults. J Orthop Sci 2015;20:71-77.

68. Boltz MM, Hollenbeak CS, Julian KG, et al. Hospital costs associated with surgical site infections in general and vascular surgery patients. Surgery 2011;150:934-942.

69. Nakahira S, Shimizu J, Miyamoto A, et al. Proposal for a sub-classification of hepato-biliary-pancreatic operations for surgical site infection surveillance following assessment of results of prospective multicenter data. J Hepatobiliary Pancreat Sci 2013;20:504-511.

70. Wick EC, Vogel JD, Church JM, et al. Surgical site infections in a "high outlier" institution: Are colorectal surgeons to blame? Dis Colon Rectum 2009;52:374379.

71. Ata A, Lee J, Bestle SL, et al. Postoperative hyperglycemia and surgical site infection in general surgery patients. Arch Surg 2010;145:858-864.

72. Pathak A, Saliba EA, Sharma S, et al. Incidence and factors associated with surgical site infections in a teaching hospital in Ujjain, India. Am J Infect Control 2014;42:e11-15.

73. Harbarth S, Huttner B, Gervaz P, et al. Risk factors for methicillin-resistant Staphylococcus aureus surgical site infection. Infect Control Hosp Epidemiol 2008;29:890-893.

74. Haridas M, Malangoni MA. Predictive factors for surgical site infection in general surgery. Surgery 2008;144:496-501. 
75. Suehiro T, Hirashita T, Araki S, et al. Prolonged antibiotic prophylaxis longer than 24 hours does not decrease surgical site infection after elective gastric and colorectal surgery. Hepatogastroenterology 2008;55:1636-1639.

76. Willis-Owen CA, Konyves A, Martin DK. Factors affecting the incidence of infection in hip and knee replacement: An analysis of 5277 cases. J Bone Joint Surg Br 2010;92:11281133.

77. Mraovic B, Suh D, Jacovides C, et al. Perioperative hyperglycemia and postoperative infection after lower limb arthroplasty. J Diabetes Sci Technol 2011;5:412-418.

78. Peersman G, Laskin R, Davis J, et al. Prolonged operative time correlates with increased infection rate after total knee arthroplasty. HSS J 2006;2:70-72.

79. Cordero-Ampuero J, de Dios M. What are the risk factors for infection in hemiarthroplasties and total hip arthroplasties? Clin Orthop Relat Res 2010;468:3268-3277.

80. Ogihara H, Takeuchi K, Majima Y. Risk factors of postoperative infection in head and neck surgery. Auris Nasus Larynx 2009;36:457-460.

81. Campbell DA, Jr., Henderson WG, Englesbe MJ, et al. Surgical site infection prevention: The importance of operative duration and blood transfusion-Results of the first American College of Surgeons-National Surgical Quality Improvement Program Best Practices Initiative. J Am Coll Surg 2008;207:810-820.

82. Watanabe A, Kohnoe S, Shimabukuro R, et al. Risk factors associated with surgical site infection in upper and lower gastrointestinal surgery. Surg Today 2008;38:404-412.

83. George AK, Srinivasan AK, Cho J, et al. Surgical site infection rates following laparoscopic urological procedures. J Urol 2011;185:1289-1293.

84. Neuman D, Grzebieniak Z. Surgical site infection-The authors' own prospective research. Pol Przegl Chir 2014; 86:26-32.

85. Mavros MN, Athanasiou S, Alexiou VG, et al. Risk factors for mesh-related infections after hernia repair surgery: A meta-analysis of cohort studies. World J Surg 2011;35: 2389-2398.

86. American College of Surgeons. What are the surgical specialties? 2016. [Available from: www.facs.org/education/ resources/medical-students/faq/specialties (Last accessed July 29, 2017).

87. Meakins JL. Surgical infection: In: Meakins JL (ed): Diagnosis and Treatment. New York: Scientific American, 1994.
88. Tweed C. Prevention of surgical wound infection: Prophylactic antibiotics in colorectal surgery. J Wound Care 2005; 14:202-205.

89. Malone DL, Genuit T, Tracy JK, et al. Surgical site infections: Reanalysis of risk factors. J Surg Res 2002;103: 89-95.

90. Anderson DJ, Podgorny K, Berríos-Torres SI, et al. Strategies to prevent surgical site infections in acute care hospitals: 2014 update. Infect Control Hosp Epidemiol 2014; 35(Suppl 2):605-627.

91. Salkind AR, Rao KC. Antibiotic prophylaxis to prevent surgical site infections. Am Fam Phys 2011;83:585-590.

92. Bratzler DW, Dellinger EP, Olsen KM, et al. Clinical practice guidelines for antimicrobial prophylaxis in surgery. Am J Health Syst Pharm 2013;70:195-283.

93. Bennett-Guerrero E, Welsby I, Dunn TJ, et al. The use of a postoperative morbidity survey to evaluate patients with prolonged hospitalization after routine, moderate-risk, elective surgery. Anesth Analg 1999;89:514-519.

94. Hoekstra LT, van Trigt JD, Reiniers MJ, et al. Vascular occlusion or not during liver resection: The continuing story. Dig Surg 2012;29:35-42.

95. Sessler DI, Akca O. Nonpharmacological prevention of surgical wound infections. Clin Infect Dis 2002;35:13971404.

96. Enzler MJ, Berbari E, Osmon DR. Antimicrobial prophylaxis in adults. Mayo Clin Proc 2011;86:686-701.

97. Frecker MI, Powell KM, Haluck R. Design of a multifunctional compliant instrument for minimally invasive surgery. J Biomech Eng 2005;127:990-993.

98. Daley BJ, Cecil W, Clarke PC, et al. How slow is too slow? Correlation of operative time to complications: An analysis from the Tennessee Surgical Quality Collaborative. J Am Coll Surg 2015;220:550-558.

99. Cheng H, Soleas IM, Ferko NC, et al. Hospital costs associated with thyroidectomy performed with a Harmonic device compared to conventional techniques: A systematic review and meta-analysis. J Med Econ 2016;19:750-758.

Address correspondence to: Hang Cheng Ethicon Inc. 4545 Creek Road Cincinnati, $\mathrm{OH} 45242$

E-mail: hcheng1@its.jnj.com 